\title{
Reseña bibliográfica: Escudero, E. (Comp.) (2020). No tan pequeños universos. Intelectuales, cultura y política en Río Cuarto, siglo XX. Río Cuarto: Unirío editora, 195 pp.
}

\author{
Palabras claves: Intelectuales - Cultura - Política - Río Cuarto - Historia Local y \\ Regional
}

Keywords: Intellectuals - Culture - Politics - Río Cuarto - Local and Regional History

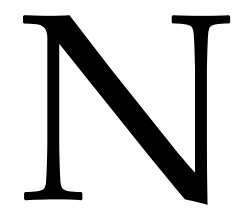
o tan pequeños universos es un libro que da cuenta de la dinámica cultural de la ciudad de Río Cuarto de la primera mitad del siglo XX, de las intervenciones culturales y políticas que realizaron quienes pensaron, escribieron y crearon mundos desde, y en muchos casos para, esa localidad del interior de la provincia de Córdoba.

Abre la serie Carlos Pérez Zabala con el artículo "Andrés Terzaga. Literato. Ensayista y pensador riocuartense", en el que se propone rescatar del olvido o del desconocimiento a quien considera uno de los dos grandes escritores que ha dado esta ciudad. El otro es Juan Filloy.

La obra de Terzaga, dice Pérez Zabala, se desarrolla principalmente en la segunda década del siglo XX, período en el que Río Cuarto muestra una activa vida cultural y social. No obstante, el mercantilismo y el desmedido afán de lucro que Terzaga ve en sus coterráneos le lleva a criticar con dureza a la sociedad riocuartense de ese período. Aunque sus reproches, para Pérez Zabala, tienen como destino final a la sociedad argentina toda.

La visión pesimista, sombría, y de cierta soledad que se refleja en los escritos de Terzaga, se contrapone muchas veces, según el autor de este artículo, con una postura existencial valiente, un amor a la vida misma que lo impulsa, lo proyecta a la creación, a la intemperie de un mundo por hacer. Objetivo, en definitiva, de su vida y su obra.

En "Arielismo y Socialismo en Río Cuarto", Osvaldo Prieto rescata y analiza el discurso social y político del socialismo local y regional. Al mismo tiempo que señala, la influencia que tuvo sobre este espacio político el pensamiento del uruguayo José Enrique Rodó y su "arielismo".

Para llevar adelante esta tarea, el autor establece cuatro apartados. En el primero, se introduce en el pensamiento de Rodó y sus derivas en el espacio latinoamericano. En el 
segundo, analiza la revista Ariel, editada en Río Cuarto en 1926, destacando su discurso crítico, sus relaciones con el feminismo, su marcado obrerismo y su juvenilismo. El tercer apartado está dedicado a los temas abordados por la revista: la cuestión obrera, la mujer, el juvenilismo, la educación y el humanismo, la crítica social, el antiimperialismo y el antibelicismo, el anticlericalismo y el periodismo. En el cuarto y último apartado, Prieto examina la influencia del arielismo en el escritor, poeta, ensayista, publicista y socialista riocuartense, Antonio Sosa Avendaño, director y administrador de la revista Ariel.

De este modo, el artículo reconstruye parte de la memoria intelectual riocuartense, aquella ligada a un pensamiento alternativo opuesto al proceso modernizador de los años veinte. Depositario del idealismo y el espiritualismo de Rodó, de su oposición al materialismo y el imperialismo norteamericano, y de su apuesta a la integración latinoamericana. Ideas que se materializarían en la revista Ariel, publicación de la cual surgieron significativas personalidades del socialismo local, entre ellos, Sosa Avendaño.

En el trabajo "Filloy en Río Cuarto, hacer desde los márgenes", Candelaria De Olmos muestra cómo el joven Juan Filloy, arribado a Río Cuarto procedente de Córdoba a comienzos de la década del '20 fue construyéndose como intelectual desde una ciudad del interior provinciano, la que, a su vez, dice la autora, le resultó favorable para ello.

En este artículo, De Olmos reconstruye la labor efectuada por Filloy en los diarios y revistas locales para forjar su imagen de escritor y su perfil intelectual. Como columnista de El Pueblo, escribiría notas de color y columnas de opinión. En Iris, una revista tipo magazine de interés general, mostraría su veta poética. Numerosas conferencias, que luego serían reproducidas en las páginas del periódico mencionado, completaban su intensa actividad cultural en Río Cuarto y la región.

Filloy escribía y publicaba, dice la autora, desde un lugar de carencias, desde un espacio periférico respecto de otros centrales como Buenos Aires o Córdoba capital. Territorios donde estas prácticas intelectuales habrían tenido un mayor lucimiento y un resultado más beneficioso para la trayectoria del escritor. Sin embargo, concluye De Olmos, será desde este "pueblito de Córdoba", escogido como su base de operaciones culturales e intelectuales, desde donde logró el reconocimiento y la inmortalidad.

En "Cosecha de ideales en una encrucijada política: el Dr. Carlos J. Rodríguez y su programática para la 'Nueva Argentina Radical'", Eduardo Escudero y Rebeca Camaño Semprini examinan el lugar que ocupó el Dr. Carlos Rodríguez en el entramado del radicalismo de la provincia de Córdoba en los años treinta y las ideas de reforma social que propició desde ese espacio político.

Escudero y Camaño Semprini señalan que la acción política de Rodríguez se desarrolló en plena década del treinta, etapa en la que se propusieron e implementaron en Argentina experiencias corporativas como las encabezadas por el General Uriburu. En ese contexto, el político riocuartense buscó su lugar entre la inteligencia política del país. Lo hizo imaginando una relación diferente entre la sociedad y el Estado, una nueva democracia que integrara de manera proporcional la representación de los Partidos Políticos con la de los grupos sociales y profesionales del país. Aunque muy similares a 
los ensayos corporativos europeos, Rodríguez entendía que estas ideas eran la única salida a la crisis que atravesaba el Estado liberal desde los años veinte. Un instrumento que en manos de la Unión Cívica Radical evitaría el salto hacia el precipicio de la revolución o el golpe de estado.

Por otra parte, los autores destacan que Rodríguez desarrolla y promueve estas ideas en momentos en el que el radicalismo de Córdoba asiste al desplazamiento de los sectores vinculados a la Iglesia Católica y al patriciado local, tradicionalmente dominantes de la estructura partidaria, y su reemplazo por una juventud renovadora encabezada por Amadeo Sabattini. En ese marco, el dirigente riocuartense se transforma en uno de los tres protagonistas que pugnan por el predominio interno en esa fuerza política. Los otros dos son el ya nombrado Sabattini y Garzón Agulla.

En el siguiente trabajo, "Juan Vázquez Cañas: Ideas y representaciones de un intelectual interiorano acerca de la crisis de la cultura y de la educación (Río Cuarto, 1930-1950)", Eduardo Escudero examina la figura de Juan Vázquez Cañas, docente, pedagogo, político y actor educacional riocuartense del que se sabe muy poco. En su análisis, Escudero recurre a una caracterización del personaje estudiado. Destaca su pertenencia a la burocracia educativa provincial y local, el ejercicio de la docencia, la animación cultural, literaria e historiográfica, su dedicación a la escritura, a la divulgación filosófico-pedagógica y alguna participación política-partidaria en la UCR.

El artículo exhibe, también, a un Vázquez Cañas preocupado por la crisis cultural y política que atravesaba la civilización contemporánea, lo que le lleva a proponer, dice el autor, un llamado civilizatorio que recuperase los valores del humanismo renacentista y evitara de esta manera que la humanidad cayese en el fascismo o el comunismo.

Para Escudero, el exhorto civilizatorio de Vázquez Cañas está presente, también, en sus ideas pedagógicas. En ellas, hay un desafío al andamiaje educativo positivista de la época, una postura anticientificista $y$ antimaterialista. Un posicionamiento epistemológico desde el que reclama un papel central para la escuela, a la que concibe neutral a las pasiones ajenas a la educación y para los maestros a los que entiende libres, tolerantes, alejados de la pedagogía libresca y equidistantes de las ideas libertarias.

En el texto “Alberto Marcos Etkin (1905-1984), intelectualidad y polémica desde Río IV, anotaciones para su biografía", Omar Isaguirre nos revela la labor de otro riocuartense que se destacó en el ambiente intelectual, profesional y artístico por los años treinta del siglo XX. Isaguirre detalla los rasgos biográficos de Etkin, su formación académica en el Colegio Nacional de Río Cuarto, su titulación como abogado en la facultad de Derecho de la Universidad de Buenos Aires en 1927 y su temprano vínculo profesional y político con el diputado nacional y figura del radicalismo cordobés, Carlos Rodríguez.

Ya instalado en Río Cuarto, puede vérsele, dice Isaguirre, peticionando junto a sus colegas por modificaciones a la legislación provincial con incumbencia en su profesión: la abogacía. Interactúa con otros intelectuales riocuartenses como Juan Filloy y Andrés 
Terzaga y escribe los numerosos estudios literarios, filosóficos, sociológicos y jurídicos que fueron publicados en medios especializados del país.

Finalmente, el autor de este artículo expone las ideas políticas de Etkin. Al respecto, señala que fue simpatizante y afiliado radical y que su mayor contribución a este partido la realizó a través de "Bosquejo de una Historia y Doctrina de la Unión Cívica Radical", un libro de su autoría que fue editado en 1928 y en el que define su militancia radical.

Cierran la compilación Griselda Pécora y Eduardo Escudero con el artículo "Situación de la intelectualidad argentina, lectura antiimperialista e imaginación histórica en Vertical, Río Cuarto 1954-1956", en el que indagan sobre la postura asumida por un sector de la intelectualidad riocuartense frente a la primera experiencia peronista y su derrocamiento en 1955. En su análisis, acuden al estudio de los discursos que aparecen en las editoriales de la Revista Vertical, publicada entre los años 1954 y 1956.

Sobre esta publicación, los autores señalan que presenta un muy variado y denso material temático: teatro, poesía, música, plástica, notas sobre libros y artículos científicos de actualidad. Sus responsables y fundadores, Helem Glauce Baldovin, Juan Armando Floriani y José Horacio Cabral Magnasco fueron, durante esta etapa, militantes del Partido Comunista.

Con respecto a la línea editorial de la revista, Pécora y Escudero sostienen que, desde sus inicios, la misma se hizo eco de lo que sería, a nivel nacional, la usina ideológica y filosófica del antiperonismo que hacía de los postulados esgrimidos por la intelectualidad liberal de Mayo de 1810 y de la Generación de 1937 un bastión "en contra de la tiranía” y "a favor de la democracia”. Esta tradición de Mayo continuó presente en sus páginas luego del golpe del '55, ahora para hacer frente a la avanzada proscriptiva de 1956 impuesta por Aramburu y Rojas.

El antiimperialismo, señalan los autores, fue otro tópico muy presente en Vertical. En sus notas y editoriales, mostraban su preocupación frente a la penetración cultural norteamericana y el impacto negativo que, según entendían, provocaba esta “infiltración" sobre las características espirituales del ser nacional, el arte y la literatura local.

Comunismo más liberalismo, más antiimperialismo norteamericano, más nacionalismo, concluyen Pécora y Escudero, fueron elementos difíciles de conjugar en el plano de la práctica política, pero estuvieron presentes en la cambiante opinión y representaciones de esa intelectualidad del interior del país. Tales dilemas promovieron, nos dicen, la desarticulación del grupo rector y fundador de Vertical y la desaparición de la revista.

La aparición de esta obra es una muestra de la vitalidad que han adquirido en los últimos años los estudios de historia argentina a escala local y regional. Los esfuerzos que se han realizado en este campo nos han permitido el acercamiento comprensivo a una realidad social determinada en un espacio acotado, la de nuestros pueblos y ciudades, sin que ello implique caer en los defectos de las historias "localistas" imbuidas muchas veces de un vago parroquianismo. A nuestro juicio, su valor radica en que nos 
muestra la existencia de universos culturales e intelectuales a menudo desconocidos o poco valorados, cuando no subestimados. Sacarlos a la superficie y apreciar sus contribuciones constituye el aporte central del trabajo que los autores ponen en manos del lector.

Gerardo Russo

Instituto Municipal de Historia de Villa María gerardo.russo@villamaria.gob.ar

Para citar esta reseña:

Russo, Gerardo (2021): Reseña bibliográfica, “Escudero, E. (Comp.) (2020). No tan pequeños universos. Intelectuales, cultura y política en Río Cuarto, siglo XX, Río Cuarto: Unirío editora, 195 pp." Anuario de la Escuela de Historia Virtual 19, 202-206. 